\title{
Long-Term Association Between Intensive Medical Treatment and The Incidence of Cardiovascular Outcomes in Patients with Dyslipidemia: an Observational Study
}

\author{
Guilherme Renke ( $\nabla$ renke@renke.com.br) \\ Instituto Nacional de Cardiologia \\ Annie Moreira \\ Instituto Nacional de Cardiologia \\ Marcela Pereira \\ Nutrindo Ideais Performance and Nutrition Research Centre \\ Débora Gapanowicz \\ Instituto Nacional de Cardiologia \\ Fernanda Mattos \\ Hospital Universitário Clementino Fraga Filho \\ Marcelo Ribeiro-Alves \\ Oswaldo Cruz Foundation
}

\section{Research Article}

Keywords: dyslipidaemia, intensive care, cardiovascular outcomes.

Posted Date: January 21st, 2022

DOI: https://doi.org/10.21203/rs.3.rs-1268594/v1

License: (c) (i) This work is licensed under a Creative Commons Attribution 4.0 International License.

Read Full License 


\section{Abstract}

\section{Background}

The management of patients with dyslipidaemia requires intensive medical follow-up as an essential part of treatment. We investigated the effect of intensive treatment on people with multiple risk factors for dyslipidaemia detected via screening. Here, we report the results of a retrospective 7-year follow-up analysis aimed at establishing whether differences in treatment and cardiovascular risk factors have been maintained and assessing their effects on cardiovascular outcomes.

\section{Methods}

This retrospective study involving 92 patients treated at the Lipid and Diabetes Service of the National Institute of Cardiology between January 1, 2012 and December 31, 2018. The patients were divided into two groups: the REG group, composed of 64 patients who had medical appointments from 2012 to 2018 (with the last appointment held between January 1 and December 31, 2018), and the DROP group, composed of 28 patients who had medical appointments in 2012 but did not complete regular appointments until 2018.

\section{Results}

In evaluating the number of cardiovascular events by follow-up time between groups, we observed a total of 32 cases of myocardial infarction [Cl $95 \% 0.08$ (0.05-0.11)] in the studied population, with $26.6 \%$ in the REG group and $53.6 \%$ in the DROP group $(p<0.001)$. There was no statistically significant difference in the stroke and hospitalization between the two groups.

\section{Conclusions}

The analysis of cardiovascular outcomes in the studied population provides a greater understanding of the importance of intensive medical treatment, and there seems to be a benefit of a reduction in cardiovascular events, especially acute myocardial infarction, in patients who complete a greater number of medical appointments and receive multidisciplinary treatment on a regular basis.

Trial registration: 31565920.3 .0000 .5272

\section{Background}

Cardiovascular diseases (CVDs) are the leading cause of mortality worldwide. According to data from NHANES 2015-2018, the prevalence of CVD was $49.2 \%$ overall in adults $\geq 20$ years of age (126.9 million in 2018), and it increased with age in both men and women [1, 2].

Several risk factors contribute to the aetiology and development of CVD, especially dyslipidemia (DLP) and diabetes mellitus (T2DM). Although contemporary data show a significant decrease in CVD rates in 
individuals with DLP and T2DM, both diseases remain highly prevalent and are important risk factors for CVD. A comprehensive and aggressive approach to the treatment of cardiovascular (CV) risk factors in adults with DLP and T2DM reduces CV events. The intensive treatment of DLP in adults with T2DM is discussed in the relevant sections of the latest guidelines of the Brazilian Society of Cardiology, the European Society of Cardiology and the American Heart Association [1-4].

Although there is robust evidence regarding the long-term efficacy of clinical treatment for controlling individual risk factors in patients with DLP and T2DM, little is known about the effect of intensive multidisciplinary or multifactorial strategies that affect the various risk factors of patients with established CVD [5].

High-risk CV patients with long-standing DLP and T2DM have a 50\% reduction in the risk of CV events and mortality when they receive intensive multidisciplinary treatment [5].

After 5 years of multidisciplinary treatment, the rate of CV events (including mortality, CV morbidity and revascularization) is $17 \%$ lower in patients undergoing intensive treatment than in those undergoing usual treatment [6].

The results of the Steno2 study in Denmark also showed that a multifactorial intervention to control glucose, blood pressure and lipids had beneficial effects on microvascular and macrovascular complications and on mortality in patients with DLP, T2DM and high CV risk [7].

Evaluating the long-term effects of a multidisciplinary intervention, including medical and nutritionist consultations, can assist in the development of guidelines, education and training regarding CV outcomes for primary care teams [5].

Chronic diseases related to nutrition, such as CVD and T2DM, represent an increasingly significant health burden for the population. Given the ability of dietary modification to improve the biomarkers of chronic diseases, the participation of nutritionists in promoting behaviour changes is recognized as a first-line approach for $\mathrm{CV}$ diseases [8].

Intensive follow-up with regular medical and nutritional consultations is essential to ensure that patients correctly adhere to drug treatments and achieve their therapeutic goals [9]. Among almost all acute myocardial infarction (AMI) patients, approximately half discontinue medications 12 months after the AMI. A higher number of consultations is associated with greater adherence to medications, lower mortality, lower morbidity and lower costs for the health system [10].

Thus, the objective of our study was to evaluate how adherence to multidisciplinary treatment and a greater number of medical consultations affect CV outcomes in patients with DLP and T2DM who were followed up for 7 years.

\section{Methods}




\subsection{Ethical aspects}

The present research project was developed according to the recommendations of resolution no. 466/2012 and the Declaration of Helsinki, modified in Hong Kong in 1989, for research involving humans. The research project was submitted to and approved by the Research Ethics Committee of the National Institute of Cardiology (NIC) and was registered with the National Research Ethics System on June 9, 2020 (31565920.3.0000.5272). The informed consent form was sent by mail and digitally, and consent was given digitally and through an audio recording due to the COVID-19 pandemic. The researchers maintained the confidentiality and integrity of the information.

\subsection{Study design and population}

This was a retrospective study involving patients treated at the Lipids and Diabetes Service of the NIC from January 1, 2012, to December 31, 2018. Convenience sampling of all patients with DLP who were treated at the outpatient clinic of the NIC in 2012 was used. Ninety-two patients were divided into two groups: The REG group, which comprised 64 patients who maintained medical appointments from 2012 to 2018 (with the last consultation performed between January 1 and December 31, 2018), and the DROP group, which comprised 28 patients who underwent medical consultations in 2012 but did not continue regular consultations until 2018.

To be included, patients were required to have the following two characteristics: 1 . Being adult of either sex aged between 35 and 75 years and 2. Having attended the DLP and T2DM services of the NIC in 2012.

Cancer patients, wheelchair users, pregnant women, lactating women and patients with active tuberculosis, mental alienation, multiple sclerosis, leprosy, Parkinson's disease, ankylosing spondylarthrosis, severe nephropathy, advanced stages of Paget's disease and acquired immunodeficiency syndrome were excluded.

The participants' clinical variables were recorded on a specific form and included their name, age, sex, history of smoking, physical exercise, systemic arterial hypertension (SAH), T2DM, angina, previous diseases, CV events (AMI, stroke, hospitalization and CV-related death) and number of outpatient medical visits during the study period. All medical records of patients treated at the outpatient clinic of the DLP and T2DM services were evaluated throughout 2012. To evaluate possible deaths, changes in address indicating a move to another city and follow-up treatment at other hospitals, the patients were contacted by telephone, and the information that was acquired was added to a form developed specifically for the study.

Adherence was assessed according to the number of consultations completed during the 7-year study period, and patients were deemed adherent to multidisciplinary treatment if they had completed at least two annual visits to the outpatient clinic and at least one consultation with the nutritionist during the 7- 
year study period. Adherence to drug treatment could not be evaluated in this study; however, it was possible to determine the profile of the drugs that the patients used during the study period.

The anthropometric variables analysed were weight, height, body mass index, waist circumference and blood pressure.

The patients' laboratory test results were analysed and compared at two time points: 2012 and 2018. Our analysis included the following tests: total cholesterol, LDL cholesterol, HDL cholesterol, triglycerides, fasting glycaemia, glycated haemoglobin, creatine phosphokinase and C-reactive protein.

Cardiovascular events and outcomes that occurred between 2012 and 2018 were collected from a medical record review and included CV disease-related death, AMI, stroke, hospitalization (with a description of the cause) and the date of the event.

\subsection{Statistical analysis}

The collected data were tabulated in a Microsoft Excel spreadsheet using the double-entry technique for validation.

In the evaluation of the differences in sociodemographic, clinical and laboratory characteristics between the two groups, for continuous numerical variables, the Mann-Whitney test was used to evaluate the hypothesis that the different samples were taken from the same distribution or from distributions with the same median. Similarly, for categorical nominal variables, chi-square tests were used to evaluate the differences in frequencies between the different groups to verify the hypothesis of independence between the groups and these variables. In addition, Pearson classification correlation coefficient analyses were estimated for continuous numerical variables. Pairwise comparisons of laboratory variables between groups were performed using contrasts obtained from multivariate linear models using adjusted ordinary least squares regressions. The $P$ values were corrected using the Tukey honest significant difference (HSD) method. To eliminate sample bias, confounding variables were selected using bivariate linear models adjusted using ordinary least squares regressions and were included in the multivariate models if the adjusted $P$ value was < 0.2. All statistical analyses were performed in $R$ v. 3.6.1. Results with a twotailed $p<0.05$ were considered significant.

\section{Results}

A total of 124 medical records of patients treated at the lipid and diabetes outpatient clinic during 2012 were evaluated. The REG group consisted of 64 patients who were followed up until 2018, and the DROP group comprised 28 patients who did not continue treatment until 2018. A total of 32 patients were excluded, including 3 patients who were under 35 years of age and 28 patients with chronic disabling diseases who were older than 76 years of age (Figure 1). The study population had a mean age of approximately 67 years, and most were men (54.3\%), elderly (58.7\%), white (58.7\%) and married (63.3\%). We observed that the patients who were most active in the labour market were the least adherent to regular treatment; these patients comprised $71.4 \%$ of the DROP group and $45.3 \%$ of the REG group ( $p=$ 
0.002). Regarding education, $30.7 \%$ of the participants had at least 10 years of education (Table 1 ). Regarding anthropometric parameters, patients with a body mass index (BMI) of $28.25 \mathrm{~kg} / \mathrm{m} 2$ (overweight: 25.0 to $29.9 \mathrm{~kg} / \mathrm{m} 2$ ) were considered overweight according to the World Health Organization classification. The mean systolic blood pressure of the study population was $136 \mathrm{mmHg}$, the diastolic blood pressure was $80 \mathrm{mmHg}$, and $93.5 \%$ of the individuals had a diagnosis of SAH. This finding was correlated with the $75 \%$ prevalence rate for diabetes 2 or prediabetes (HbA1c $>5.7 \%$ ). A total of $46.7 \%$ of the studied patients had current or previous angina, indicating that the study population had a high degree of CV risk. Regarding lifestyle, the prevalence of a sedentary lifestyle was $83.7 \%$, and the prevalence of smoking was $30.4 \%$. 
Table 1. General characteristics of the study participants, previous events at baseline and comparisons between groups.

\begin{tabular}{lllll} 
VARIABLES & TOTAL & REG & DROP & P \\
\cline { 2 - 5 } & $(n=92)$ & $(n=64)$ & $(n=28)$
\end{tabular}

\section{DATA}

\begin{tabular}{|lllll|}
\hline Age (years) & $67(\mathrm{IQR}=9.25)$ & $\begin{array}{l}67 \\
(\mathrm{IQR}=10.25)\end{array}$ & $\begin{array}{l}66 \\
(\mathrm{IQR}=6.75)\end{array}$ & 0.489 \\
\hline Men - $\mathrm{n}(\%)$ & $50(54.3 \%)$ & $33(51.6 \%)$ & $17(60.7 \%)$ & 0.560 \\
\hline Women - $\mathrm{n}(\%)$ & $42(45.7 \%)$ & $31(48.4 \%)$ & $11(39,3 \%)$ & 0.607 \\
\hline Elderly ( $\geq 65$ years) - n (\%) & $54(58.7 \%)$ & $37(57.8 \%)$ & $17(60.7 \%)$ & 0.976
\end{tabular}

\section{DEMOGRAPHIC DATA}

\begin{tabular}{|c|c|c|c|c|}
\hline Marital status (married) - $\mathrm{n}(\%)$ & $50(54.3 \%)$ & $35(54.7 \%)$ & $15(53.6 \%)$ & 0.181 \\
\hline $\begin{array}{l}\text { Schooling (complete elementary school) } \\
\text { - } \mathrm{n}(\%)\end{array}$ & $23(25 \%)$ & $14(21.9 \%)$ & $9(32.1 \%)$ & 0.632 \\
\hline Occupation (active) - n (\%) & $49(53.3 \%)$ & $29(45.3 \%)$ & $20(71.4 \%)$ & 0.002 \\
\hline Race/colour (white) - n (\%) & $54(58.7 \%)$ & $41(64.1 \%)$ & $13(46.4 \%)$ & 0.434 \\
\hline \multicolumn{5}{|l|}{ ANTHROPOMETRIC DATA } \\
\hline Weight (kg) & $\begin{array}{l}75 \\
(\mathrm{IQR}=17.88)\end{array}$ & $\begin{array}{l}73 \\
(\mathrm{IQR}=16.4)\end{array}$ & $\begin{array}{l}80 \\
(\mathrm{IQR}=15.75)\end{array}$ & 0.024 \\
\hline BMI (kg/m2) & $\begin{array}{l}28.25 \\
(\mathrm{IQR}=5.32)\end{array}$ & $\begin{array}{l}28.1 \\
(\mathrm{IQR}=5.3)\end{array}$ & $\begin{array}{l}28.7 \\
(\mathrm{IQR}=4.67)\end{array}$ & 0.959 \\
\hline SBP $(\mathrm{mmHg})$ & $136(\mathrm{IQR}=23)$ & $\begin{array}{l}140 \\
(\mathrm{IQR}=23)\end{array}$ & $\begin{array}{l}130 \\
(\mathrm{IQR}=22.5)\end{array}$ & 0.238 \\
\hline DBP $(\mathrm{mmHg})$ & $80(\mathrm{IQR}=10)$ & $80(\mathrm{IQR}=10)$ & $80(\mathrm{IQR}=10)$ & 0.969 \\
\hline \multicolumn{5}{|l|}{ CLINICAL DATA } \\
\hline Smoking - n (\%) & $28(30.4 \%)$ & $15(23.4 \%)$ & $13(46.4 \%)$ & 0.055 \\
\hline Physical exercise - n (\%) & $15(16.3 \%)$ & $13(20.3 \%)$ & $2(7.1 \%)$ & 0.276 \\
\hline Hypertension - n (\%) & $86(93.5 \%)$ & $58(90.6 \%)$ & $28(100 \%)$ & 0.246 \\
\hline T2DM - n (\%) & $69(75 \%)$ & $52(81.2 \%)$ & $17(60.7 \%)$ & 0.064 \\
\hline
\end{tabular}

Values are expressed as $\mathrm{n}(\%)$ or median \pm IQR. Student's $\mathrm{t}$ test, chi-square test. IQR: interquartile range. * Significant difference $p<0.05$. BMI: body mass index; SBP: systolic blood pressure; DBP: diastolic blood pressure; T2DM: type 2 diabetes mellitus. 
Table 2. Previous events at baseline and comparisons between groups.

\begin{tabular}{|c|c|c|c|c|c|}
\hline \multirow[t]{2}{*}{ VARIABLES } & TOTAL & REG & DROP & \multirow[t]{2}{*}{$\mathbf{P}$} & \multirow[b]{2}{*}{ aRR (95\% Cl) } \\
\hline & $(n=92)$ & $(n=64)$ & $(n=28)$ & & \\
\hline \multicolumn{6}{|l|}{ PREVIOUS EVENTS } \\
\hline Previous disease - n (\%) & $67(72.8 \%)$ & $45(70.3 \%)$ & $22(78.6 \%)$ & 0.532 & $0,3(0.02-5.23)$ \\
\hline AMI - n (\%) & $45(48.9 \%)$ & $30(46.9 \%)$ & $15(53.6 \%)$ & 0.085 & 21.58 (1.6-290.37) \\
\hline PTCA - n (\%) & $25(27.2 \%)$ & $16(25 \%)$ & $9(32.1 \%)$ & 0.083 & $1.48(0.19-11.86)$ \\
\hline MCRS - n (\%) & $33(35.9 \%)$ & $20(31.2 \%)$ & $13(46.4 \%)$ & 0.048 & $4.1(0.52-32.62)$ \\
\hline CHF - n (\%) & $32(34.8 \%)$ & $14(21.9 \%)$ & $18(64.3 \%)$ & 0.001 & $91.99(2.69-3148.95)$ \\
\hline DCM - n (\%) & $9(9.8 \%)$ & $5(7.8 \%)$ & $4(14.3 \%)$ & 0.067 & $0.22(0.01-3.68)$ \\
\hline Aneurysm - n (\%) & $1(1.1 \%)$ & $1(1.6 \%)$ & $0(0 \%)$ & 0.065 & \\
\hline Arrhythmias - n (\%) & $21(22.8 \%)$ & $8(12.5 \%)$ & $13(46.4 \%)$ & 0.001 & $46.44(0.98-2192.33)$ \\
\hline History of angina - n (\%) & 43 (46.7\%) & $29(45.3 \%)$ & $14(50 \%)$ & 0.614 & $1.48(0.25-8.79)$ \\
\hline
\end{tabular}

Values are expressed as $n(\%)$. Student's $t$ test, chi-square test.* Significant difference $p<0.05$. AMl: acute myocardial infarction; PTCA: percutaneous transluminal coronary angioplasty; MCRS: myocardial revascularization surgery; CHF: congestive heart failure; DCM: dilated cardiomyopathy; aRR:Adjusted Relative Ratio, where Age, Sex, BMI, Ethnicity, Marital status, Occupation, and Schooling-years were included in multiple binomial models.

Both groups were homogeneous except for the higher prevalence of previous congestive heart failure and arrhythmias in the DROP group $(p=0.001)$. In the REG group, we observed a higher prevalence of myocardial revascularization surgery than in the DROP group $(p<0.05)$. AMI was present in $48.9 \%$ of the study population, including $46.8 \%$ of the REG group and $53.57 \%$ of the DROP group [ $95 \% \mathrm{Cl} 21.58$ (1.6290.37)] (Table 2).

Most of the study population used 7 drugs during the study period, with a median lower than 6 $(I Q R=3)$ drugs in the REG group versus $7(I Q R=2.25)$ drugs in the DROP group ( $p 0.300)$. Statins were the most commonly used drug in the study, followed by beta blockers, antiplatelet agents, diuretics and metformin (Table 3). 
Table 3. Use of medications by the study participants at baseline and comparison between groups.

\section{VARIABLE}

\section{TOTAL \\ REG \\ DROP \\ p \\ $(n=92) \quad(n=64) \quad(n=28)$}

\section{DRUG}

\begin{tabular}{|c|c|c|c|c|c|}
\hline Beta blockers - n (\%) & $80(87 \%)$ & $\begin{array}{l}55 \\
(85.9 \%)\end{array}$ & $\begin{array}{l}25 \\
(89.3 \%)\end{array}$ & 0.888 & $\begin{array}{l}6.26(0.06- \\
687.22)\end{array}$ \\
\hline $\begin{array}{l}\text { Calcium channel blockers - } \mathrm{n} \\
(\%)\end{array}$ & $\begin{array}{l}25 \\
(27.2 \%)\end{array}$ & $\begin{array}{l}20 \\
(31.2 \%)\end{array}$ & $5(17.9 \%)$ & 0.207 & $0.13(0.01-1.53)$ \\
\hline ACEls - n (\%) & $\begin{array}{l}31 \\
(33.7 \%)\end{array}$ & $16(25 \%)$ & $\begin{array}{l}15 \\
(53.6 \%)\end{array}$ & 0.052 & $62(1.63-2359.33)$ \\
\hline ARBs - n (\%) & $\begin{array}{l}41 \\
(44.6 \%)\end{array}$ & $\begin{array}{l}31 \\
(48.4 \%)\end{array}$ & $\begin{array}{l}10 \\
(35.7 \%)\end{array}$ & 0.589 & $0.59(0.1-3.43)$ \\
\hline Statins - n (\%) & $81(88 \%)$ & $\begin{array}{l}58 \\
(90.6 \%)\end{array}$ & $\begin{array}{l}23 \\
(82.1 \%)\end{array}$ & 0.372 & $0.16(0.01-2.42)$ \\
\hline Anticoagulants - $\mathrm{n}(\%)$ & $9(9.8 \%)$ & $9(14.1 \%)$ & $0(0 \%)$ & 0.036 & \\
\hline Antiplatelets - n (\%) & $\begin{array}{l}59 \\
(64.1 \%)\end{array}$ & $\begin{array}{l}37 \\
(57.8 \%)\end{array}$ & $\begin{array}{l}22 \\
(78.6 \%)\end{array}$ & 0.567 & $2.75(0.43-17.49)$ \\
\hline Diuretics - n (\%) & $\begin{array}{l}54 \\
(58.7 \%)\end{array}$ & $\begin{array}{l}31 \\
(48.4 \%)\end{array}$ & $\begin{array}{l}23 \\
(82.1 \%)\end{array}$ & 0.021 & $\begin{array}{l}37.02(2.3- \\
594.71)\end{array}$ \\
\hline Ezetimibe - n (\%) & $\begin{array}{l}30 \\
(32.6 \%)\end{array}$ & $\begin{array}{l}28 \\
(43.8 \%)\end{array}$ & $2(7.1 \%)$ & 0.095 & $0.08(0.01-0.97)$ \\
\hline Fibrates - n (\%) & $\begin{array}{l}18 \\
(19.6 \%)\end{array}$ & $\begin{array}{l}10 \\
(15.6 \%)\end{array}$ & $8(28.6 \%)$ & 0.019 & $\begin{array}{l}46.96(2.53- \\
869.86)\end{array}$ \\
\hline Antiarrhythmics - n (\%) & $\begin{array}{l}20 \\
(21.7 \%)\end{array}$ & $8(12.5 \%)$ & $\begin{array}{l}12 \\
(42.9 \%)\end{array}$ & 0.351 & $5.1(0.48-53.92)$ \\
\hline Oral hypoglycaemics - n (\%) & $\begin{array}{l}28 \\
(30.4 \%)\end{array}$ & $\begin{array}{l}22 \\
(34.4 \%)\end{array}$ & $6(21.4 \%)$ & 0.376 & $0.23(0.03-2.04)$ \\
\hline Glinides - n (\%) & $\begin{array}{l}16 \\
(17.4 \%)\end{array}$ & $\begin{array}{l}13 \\
(20.3 \%)\end{array}$ & $3(10.7 \%)$ & 0.958 & $0.31(0.01-7.93)$ \\
\hline Metformin - $\mathrm{n}(\%)$ & $\begin{array}{l}45 \\
(48.9 \%)\end{array}$ & $32(50 \%)$ & $\begin{array}{l}13 \\
(46.4 \%)\end{array}$ & 0.968 & $2.68(0.17-42.1)$ \\
\hline Insulin - n (\%) & $\begin{array}{l}16 \\
(17.4 \%)\end{array}$ & $\begin{array}{l}11 \\
(17.2 \%)\end{array}$ & $5(17.9 \%)$ & 0.873 & $0.91(0.09-8.9)$ \\
\hline Allopurinol - n (\%) & $\begin{array}{l}17 \\
(18.5 \%)\end{array}$ & $8(12.5 \%)$ & $9(32.1 \%)$ & 0.180 & $\begin{array}{l}18.2(0.63- \\
522.91)\end{array}$ \\
\hline Adrenergic agonists - $\mathrm{n}(\%)$ & $3(3.3 \%)$ & $2(3.1 \%)$ & $1(3.6 \%)$ & 0.869 & \\
\hline \multirow[t]{2}{*}{ Nitrates - n (\%) } & 31 & 19 & 12 & 0.353 & $3.69(0.56-24.51)$ \\
\hline & & Page $9 / 19$ & & & \\
\hline
\end{tabular}


Values are expressed as $n(\%)$. Student's t test, chi-square test. ${ }^{*}$ Significant difference $p<0.05$. ACEls: angiotensin-converting enzyme inhibitors; ARBs: angiotensin receptor blockers;aHR: Adjusted Hazard Ratio, where Age, Sex, BMI, Ethnicity, Marital status, Occupation, and Schooling-years were included in multiple binomial models.

In the evaluation of the initial laboratory results at baseline (REGT1 $x$ DROPT1), we did not observe significant differences between the groups. Exceptions were HDL $(\mathrm{mg} / \mathrm{dl})$, which had medians of 39.00 overall, 41.00 at REGT1 and 33.00 at DROPT1 $(p<0.05)$, and C-reactive protein $(\mathrm{mg} / \mathrm{dl})$, which had a mean of 0.19 , including 0.13 at REGT1 and 0.69 at DROPT1 $(p<0.05)$.

In the intergroup comparison (REG x DROP) at T2 and T1, we observed significant differences in all laboratory tests except C-reactive protein $(p=0.24)$. We observed reductions in total cholesterol $(p<$ $0.001)$, LDL-c $(p<0.001)$, triglycerides $(p=0.003)$, fasting glucose $(p<0.001)$, Hba1C $(p<0.001)$ and CPK $(p<0.001)$. We observed an improvement in HDL-c levels $(p<0.001)$. In the scatter plots, we observed a positive correlation between the variables for both groups at times T1 and T2 (Figure 2).

The REG group had a median of 22 visits, and the DROP group had a median of $12.50(p<0.05)$. However, when we evaluated the number of consultations according to the follow-up time, we observed a greater number of consultations/year completed by the DROP group [ $95 \% \mathrm{Cl} 4.36$ (3.95-4.81)] than by the REG group [95\% Cl 3.38 (3.2-3.57)] ( $p$ 0.007). A total of 57 consultations with a nutritionist were observed in the study population, and $76.6 \%$ of the REG group had at least one consultation with a nutritionist, versus $28.6 \%$ of the DROP group ( $p<0.05$ ). The median follow-up time in the study was 5.72 years for both groups; in the REG group, the median time was 5.97 years, compared to 3.63 years in the DROP group $(p<0.05)($ Table 4$)$.

In the evaluation of the number of CV events and deaths during the study period, when we compared the two groups, we observed a total of 53 hospital admissions during the study period, including $45.3 \%$ in the REG group and $85.7 \%$ in the DROP group ( $p=2.338)$. A total of 32 cases of AMI were identified in the study population, including $26.6 \%$ in the REG group and $53.6 \%$ in the DROP group $(p<0.001)$. A total of 5 cases of stroke were observed, comprising $4.7 \%$ of the REG group and $7.1 \%$ of the DROP group. The total number of deaths was $64.3 \%$ higher in the DROP group, and $25 \%$ were due to MCV (Table 4). 
Table 4

Consultations and events during the study and comparison between groups according to follow-up time point.

\begin{tabular}{|c|c|c|c|c|c|}
\hline VARIABLES & TOTAL & $\begin{array}{l}\text { REG ( } n= \\
64)\end{array}$ & $\begin{array}{l}\text { DROP }(n= \\
28)\end{array}$ & $\mathbf{P}$ & $\begin{array}{l}\text { aHR }(95 \% \\
\mathrm{Cl})\end{array}$ \\
\hline $\begin{array}{l}\text { Number of ambulatory } \\
\text { consultations per patient }\end{array}$ & $\begin{array}{l}18 \\
(\mathrm{IQR}=15)\end{array}$ & $\begin{array}{l}22 \\
(\mathrm{IQR}=13)\end{array}$ & $\begin{array}{l}12.5 \\
(\mathrm{IQR}=17.25)\end{array}$ & 0.003 & \\
\hline $\begin{array}{l}\text { Consultation with a nutritionist, } \mathrm{n} \\
(\%)\end{array}$ & $57(62 \%)$ & 49 (76.6\%) & $8(28.6 \%)$ & $<0,001$ & \\
\hline Monitoring time in years, $\mathrm{n}(\%)$ & $\begin{array}{l}5.72 \\
(\mathrm{IQR}=1.37)\end{array}$ & $\begin{array}{l}5.97 \\
(\mathrm{IQR}=0.60)\end{array}$ & $\begin{array}{l}3.63 \\
(\mathrm{IQR}=2.21)\end{array}$ & $<.001$ & \\
\hline Hospitalizations, n (\%) & $53(57.6 \%)$ & $29(45.3 \%)$ & $24(85.7 \%)$ & 5,856 & $\begin{array}{l}14.452 \\
(4.552- \\
45.88)\end{array}$ \\
\hline AMI, n (\%) & $32(34.8 \%)$ & $17(26.6 \%)$ & $15(53.6 \%)$ & $<0.001$ & $\begin{array}{l}13.98 \\
(2.99- \\
65.26)\end{array}$ \\
\hline Stroke, n (\%) & $5(5.4 \%)$ & $3(4.7 \%)$ & $2(7.1 \%)$ & 0.126 & \\
\hline CVA, n (\%) & $7(7.6 \%)$ & $0(0 \%)$ & $7(25 \%)$ & $<0.001$ & \\
\hline CV death, $\mathrm{n}(\%)$ & $18(19.6 \%)$ & $0(0 \%)$ & $18(64.3 \%)$ & $<0.001$ & \\
\hline \multicolumn{6}{|c|}{$\begin{array}{l}\text { Values are expressed as } n(\%) \text {. Chi-square test. IQR: interquartile range. *Significant difference } p \\
<0.05 \text {. AMl: acute myocardial infarction; CVA: cardiovascular accident (stroke); CV death: } \\
\text { cardiovascular death.aHR: adjusted Hazard Ratio, where Age, Sex, BMI, Ethnicity, Marital status, } \\
\text { Occupation, and Schooling-years were included in multiple binomial models. }\end{array}$} \\
\hline
\end{tabular}

\section{Discussion}

We observed that despite the higher number of visits/year in the DROP group, the number of AMls by follow-up time point was higher in the DROP group than in the REG group [95\% Cl 13.98 (2.99-65.26)] (table 4). In fact, although patients with DLP should already be considered at high CV risk, the presence of additional risk factors, such as T2DM, amplifies the risk of CVD[9]. It is estimated that coronary events, fatal or not, occur in approximately $50 \%$ of men diagnosed with familial DLP before the age of 50 years and in $30 \%$ of women diagnosed before the age of 60 years. In addition, the literature indicates that the average age at CVD presentation is approximately 43 years in men and 52 years in women[11]. It is known, however, that when patients with DLP receive adequate treatment and achieve therapeutic goals, their risk of developing CVD is similar to that of the general population[11, 12]. A meta-analysis showed that intensive patient care improved patient adherence and decreased serum TC and LDL-C levels. The improvements in patient adherence and blood lipid levels were consistent with the results of randomized clinical trials with a follow-up of more than 6 months $[5,6]$. There was a similar trend in our study; we observed a significant improvement in laboratory parameters with increasing follow-up time in the REG 
group compared to the DROP group for TC, HDL-C, LDL-c, triglycerides, fasting glucose, Hba1C and CPK $(p<0.05)$. Despite this result, the DROP group completed more consultations/year than the REG group, possibly because the patients in the DROP group had a higher CV risk $(p=0.007)$. However, more patients in the REG group than the DROP group consulted with a nutritionist $(76.6 \%$ vs. $28.6 \%, p<0.001)$, showing that multidisciplinary treatment can have a positive effect on reducing outcomes (Table 4).

Another important finding was the high prevalence of T2DM in the study population. The reported prevalence of T2DM in the adult population is $12 \%$; however, in our study, this prevalence was $75 \%$, identified by glycated haemoglobin ( $\mathrm{HbA} 1 \mathrm{c}$ ) values greater than or equal to $6.5 \%$. The importance of longterm drug treatment for patients with diabetes has been demonstrated in several randomized clinical trials. Reducing blood glucose in high-risk CV patients with prediabetes or T2DM is essential. Glycaemia is a strong and independent predictor of long-term mortality in patients with CVD, and intensive blood glucose control is necessary[13]. We observed in our study that with regular medical treatment, laboratory $\mathrm{HbA1C}$ levels in the REG group remained stable at $6.5 \%$. In the DROP group, the only worsening of laboratory parameters that was observed in the entire study was that of $\mathrm{HbA} 1 \mathrm{C}$ levels, which worsened by $0.25 \%$ during the follow-up period $(p<0.05)$. However, even though no laboratory improvement was observed, regular multidisciplinary treatment of patients with T2DM was associated with reduced CV risk compared to routine care in the first 5 years after diagnosis[5].

The benefit of statin therapy is also related to the overall risk and intensity of treatment. Patients with diabetes have a higher $\mathrm{CV}$ risk than those without diabetes; high-intensity statin therapy is preferred for patients with diabetes $[12,14,15]$. However, no randomized clinical trial of treatment with high-intensity statins has been conducted in cohorts exclusively comprising patients with T2DM. In our study, statins were the most commonly used drugs; they showed similar use between groups [95\% $\mathrm{Cl} 0.16(0.01-2.42)$ ] and were used by $88 \%$ of patients, many of whom were considered high risk, having experienced events prior to our study $(72,8 \%)$. Greater adherence to drug therapy is associated with lower mortality and lower CV morbidity. In a meta-analysis, therapy associated with a $50 \%$ decrease in LDL-C led to a $15 \%$ reduction in CV outcomes[16]. In fact, we observed a trend towards greater use of statins by the REG group (90.6\%) than by the DROP group $(82.1 \%)(p=0.069)$. Early medical interventions and a greater number of consultations offer promise as a potential method for addressing this important care gap to maximize the acceptance of treatment[17]. Higher adherence to drug therapy is associated with lower mortality, lower CV morbidity and lower costs to the health system. In contrast, low adherence to prescription drug use is common, and approximately $50 \%$ of patients discontinue medication 12 months after a CV event[10].

There is growing evidence of lower overall mortality in patients who are treated by a multidisciplinary team at specialized outpatient services for dyslipidaemia and diabetes versus primary care treatment[9, 18-20]. A large study with a European population showed that after 5 years of intensive treatment compared to basic treatment, there was a greater reduction in CV risk factors. There was also an increase in the prescription of medications and a 17\% reduction in CV outcomes[9]. Interestingly, in our study, we observed a higher number of medical visits per follow-up time point in the DROP group $[95 \% \mathrm{Cl} 4.36$ 
(3.95-4.81)] than in the REG group [95\% Cl 3.38 (3.2-3.57)] ( $p=0.007)$. However, the number of consultations with a nutritionist was significantly higher in the REG group (76.6\%) than in the DROP group $(28.6 \%)$ by follow-up time point $(p<0.001)$. Thus, we suggest that a reduction in $\mathrm{CV}$ outcomes is related to greater adherence to multidisciplinary treatment by a physician and nutritionist.

\section{Conclusion}

The analysis of the CV outcomes of the studied population provides greater understanding of the importance of intensive multidisciplinary treatment. There seems to be a benefit in the form of a reduction of $\mathrm{CV}$ events, especially $\mathrm{AMI}$, in patients who undergo regular treatment. We observed that adherence to multimodal clinical treatment can serve as a source of health education and can support lifestyle changes. This presents greater possibilities for long-term clinical applications, since preventive and outpatient medical monitoring has low risk, is affordable and may represent an additional measure to incorporate into patient treatment.

\section{Abbreviations}

ACEl:angiotensin-converting enzyme inhibitors

AMI: acute myocardial infarction

ARB: angiotensin receptor blockers

BMI: body mass index

CHF: congestive heart failure

COVID-19: coronavirus disease

CPK: creatine phosphokinase

CRP: C-reactive protein.

CV: cardiovascular

CVA: cardiovascular accident (stroke)

CVD: cardiovascular diseases

DBP: diastolic blood pressure

DCM: dilated cardiomyopathy

DLP: dyslipidaemia 
DROP: dropout group

HbA1C: glycated haemoglobin

HDL-c: high-density lipoprotein

LDL-c: low-density lipoprotein

MCRS: myocardial revascularization surgery

NHANES: The National Health and Nutrition Examination Survey

NIC: National Institute of Cardiology

PTCA: percutaneous transluminal coronary angioplasty

REG: regular group

SAH: systemic arterial hypertension

SBP: systolic blood pressure;

T2DM: type 2 diabetes mellitus

\section{Declarations}

\section{Ethics approval and consent to participate}

The study protocol was approved by the ethical review committees of the Research Ethics Committee of the National Institute of Cardiology (NIC) and was registered with the National Research Ethics System on June 9, 2020 (31565920.3.0000.5272). Before interview, the written informed consent was obtained from each participant. Data were anonymised before use in this study.

\section{Consent for publication}

Not applicable

\section{Availability of data and materials}

The datasets used and/or analyzed during the current study are available from the corresponding author on reasonable request

\section{Competing interests}

The authors declare that they have no competing interests.

\section{Funding}


No funding was received for this work.

\section{Authors' contributions}

G.R and A.S.B.M, contributed to study concept and design. G.R and M.B.P, drafted the manuscript and acquired data. D.P.G, contributed to the analysis and interpretation of data. M.R.A, contributed to statistical analysis. F.M, critically revised the manuscript.

\section{Acknowledgements}

Not applicable.

\section{References}

1. Virani SS, Alonso A, Aparicio HJ, Benjamin EJ, Bittencourt MS, Callaway CW, et al. Heart disease and stroke statistics-2021 update: a report from the American Heart Association. Circulation. 2021;143:e254-743.

2. Visseren FL, Mach F, Smulders YM, Carballo D, Koskinas KC, Bäck M, et al. 2021 ESC guidelines on cardiovascular disease prevention in clinical practice: developed by the task force for cardiovascular disease prevention in clinical practice with representatives of the european society of cardiology and 12 medical societies with the special contribution of the european association of preventive cardiology (EAPC). Eur Heart J. 2021;42:3227-337.

3. Laddu D, Ma J, Kaar J, Ozemek C, Durant RW, Campbell T, et al. Health behavior change programs in primary care and community practices for cardiovascular disease prevention and risk factor management among midlife and older adults: a scientific statement from the American Heart Association. Circulation. 2021;144:e533-49.

4. Izar MCO, Giraldez VZR, Bertolami A, Santos Filho RDD, Lottenberg AM, Assad MHV, et al. Update of the Brazilian guideline for familial hypercholesterolemia - 2021. Arq Bras Cardiol. 2021;117:782-844.

5. Griffin SJ, Rutten G, Khunti K, Witte DR, Lauritzen T, Sharp SJ, et al. Long-term effects of intensive multifactorial therapy in individuals with screen-detected type 2 diabetes in primary care: 10-year follow-up of the ADDITION-Europe cluster-randomised trial. Lancet Diabetes Endocrinol. 2019;7:92537.

6. Ueki K, Sasako T, Okazaki Y, Kato M, Okahata S, Katsuyama H, et al. Effect of an intensified multifactorial intervention on cardiovascular outcomes and mortality in type 2 diabetes (J-DOIT3): an open-label, randomised controlled trial. Lancet Diabetes Endocrinol. 2017;5:951-64.

7. Diabetes Prevention Program Research Group. Long-term effects of lifestyle intervention or metformin on diabetes development and microvascular complications over 15-year follow-up: the diabetes prevention program outcomes study. Lancet Diabetes Endocrinology. 2015;3:866-75.

8. Mitchell LJ, Ball LE, Ross LJ, Barnes KA, Williams LT. Effectiveness of dietetic consultations in primary health care: a systematic review of randomized controlled trials. J Acad Nutr Diet. 
2017;117:1941-62.

9. Xie X, Atkins E, Lv J, Bennett A, Neal B, Ninomiya T, et al. Effects of intensive blood pressure lowering on cardiovascular and renal outcomes: updated systematic review and meta-analysis. Lancet. 2016;387:435-43.

10. Ivers NM, Schwalm J-D, Bouck Z, McCready T, Taljaard M, Grace SL, et al. Interventions supporting long term adherence and decreasing cardiovascular events after myocardial infarction (ISLAND): pragmatic randomised controlled trial. BMJ. 2020;369:m1731.

11. Arnett DK, Blumenthal RS, Albert MA, Buroker AB, Goldberger ZD, Hahn EJ, et al. 2019 ACC/AHA guideline on the primary prevention of cardiovascular disease: a report of the American College of Cardiology/American Heart Association task force on clinical practice guidelines. Circulation. 2019;140:e596-646.

12. Grundy SM, Stone NJ, Bailey AL, Beam C, Birtcher KK, Blumenthal RS, et al. 2018 AHA/ACC/AACVPR/AAPA/ABC/ACPM/ADA/AGS/APhA/ASPC/NLA/PCNA guideline on the management of blood cholesterol: executive summary: a report of the American College of Cardiology/American Heart Association task force on clinical practice guidelines. J AmColl Cardiol. 2019;73:3168-209.

13. LeRoith D, Biessels GJ, Braithwaite SS, Casanueva FF, Draznin B, Halter JB, et al. Treatment of diabetes in older adults: an endocrine society clinical practice guideline. J Clin Endocrinol Metab. 2019;104:1520-74.

14. Baigent C, Blackwell L, Emberson J, Holland LE, Reith C, Bhala N, et al. Efficacy and safety of more intensive lowering of LDL cholesterol: a meta-analysis of data from 170,000 participants in 26 randomised trials. Lancet. 2010;376:1670-81.

15. Campbell DJT, Lee-Krueger RCW, McBrien K, Anderson T, Quan H, Leung AA, et al. Strategies for enhancing the initiation of cholesterol lowering medication among patients at high cardiovascular disease risk: a qualitative descriptive exploration of patient and general practitioners' perspectives on a facilitated relay intervention in Alberta, Canada. BMJ Open. 2020;10:e038469.

16. Piña IL, Di Palo KE, Brown MT, Choudhry NK, Cvengros J, Whalen D, et al. Medication adherence: importance, issues and policy: a policy statement from the American Heart Association. Prog Cardiovasc Dis. 2021;64:111-20.

17. van Driel ML, Morledge MD, Ulep R, Shaffer JP, Davies P, Deichmann R. Interventions to improve adherence to lipid-lowering medication. Cochrane Database Syst Rev. 2016;12:Cd004371.

18. Versmissen J, Oosterveer DM, Yazdanpanah M, Defesche JC, Basart DC, Liem AH, et al. Efficacy of statins in familial hypercholesterolaemia: a long term cohort study. BMJ. 2008;337:a2423.

19. Nathan DM, Genuth S, Lachin J, Cleary P, Crofford O, Davis M, et al. The effect of intensive treatment of diabetes on the development and progression of long-term complications in insulin-dependent diabetes mellitus. New Engl JMed. 1993;329:977-86.

20. UK Prospective Diabetes Study (UKPDS) Group. Intensive blood-glucose control with sulphonylureas or insulin compared with conventional treatment and risk of complications in patients with type 2 
diabetes (UKPDS 33). Lancet. 1998;352:837-53.

\section{Figures}

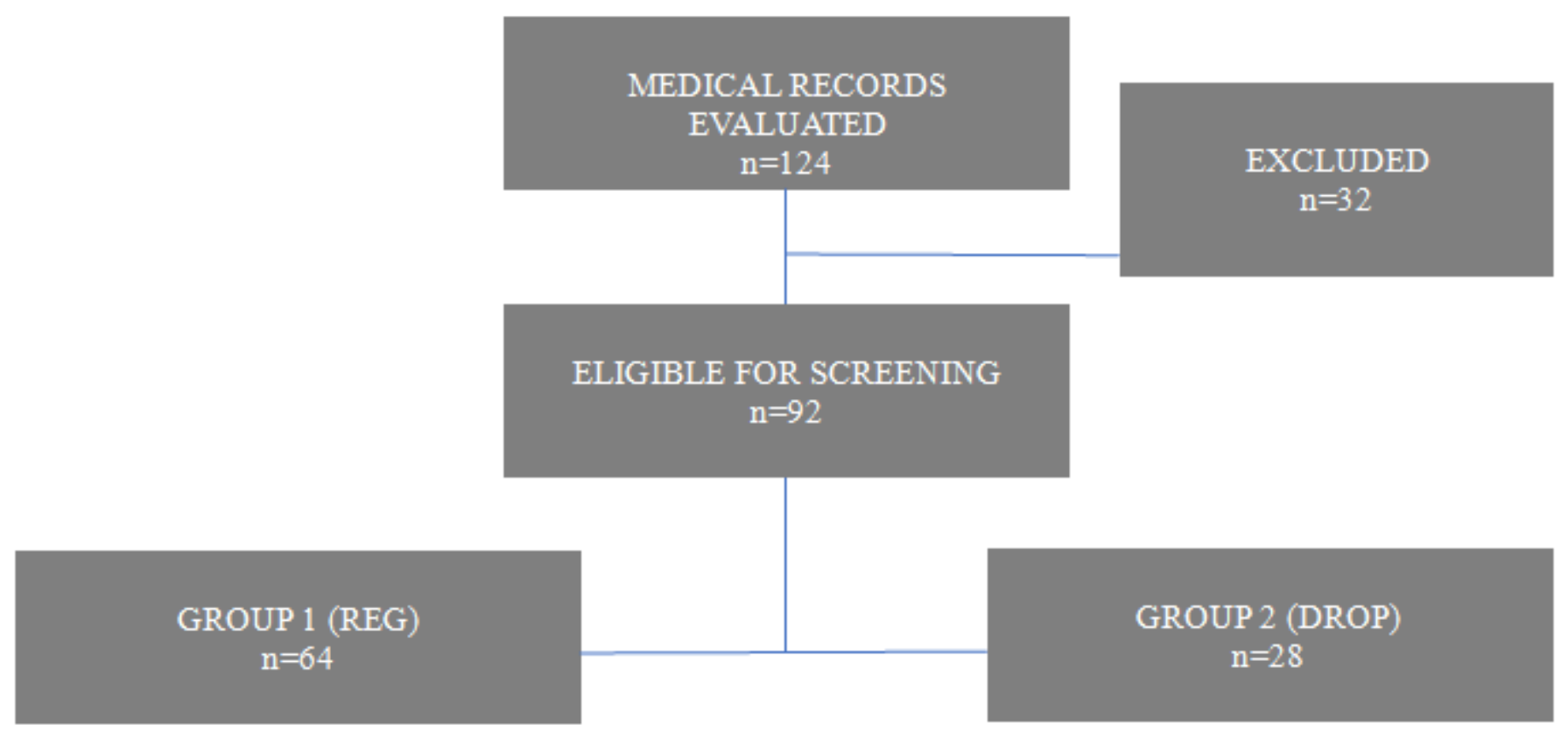

\section{Figure 1}

Recruitment flowchart for the study 
A)

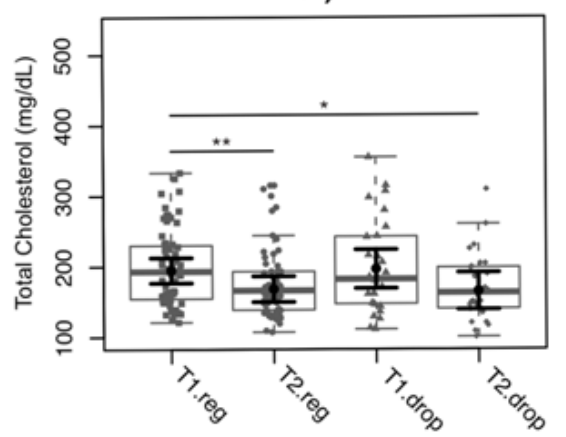

C)

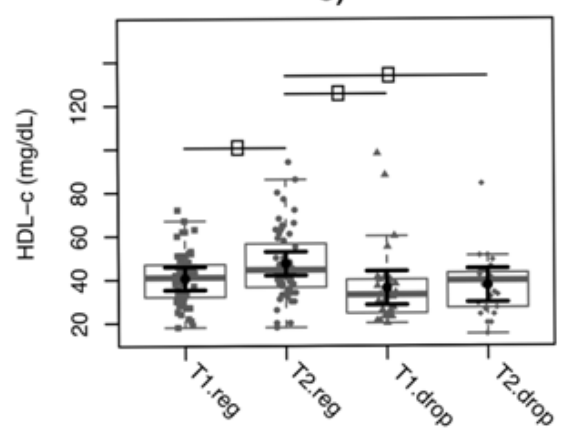

E)

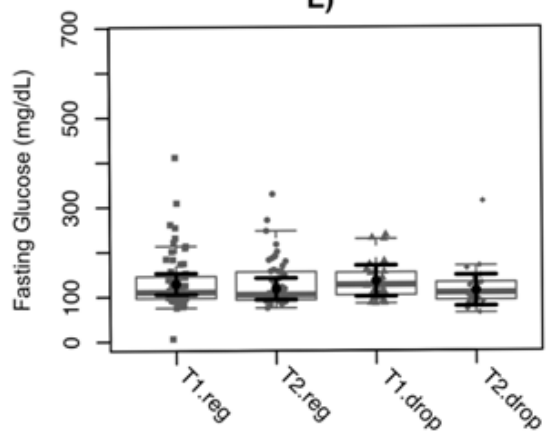

G)

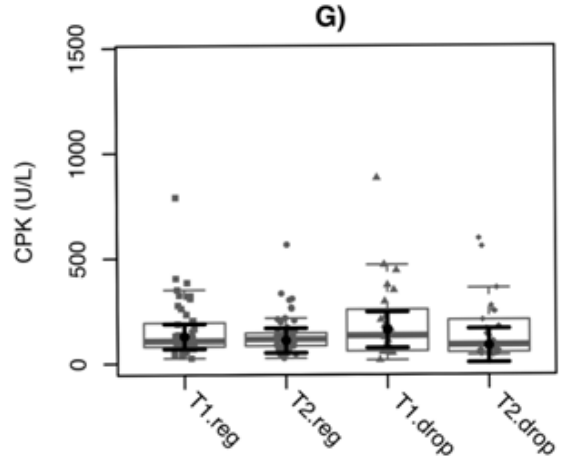

B)

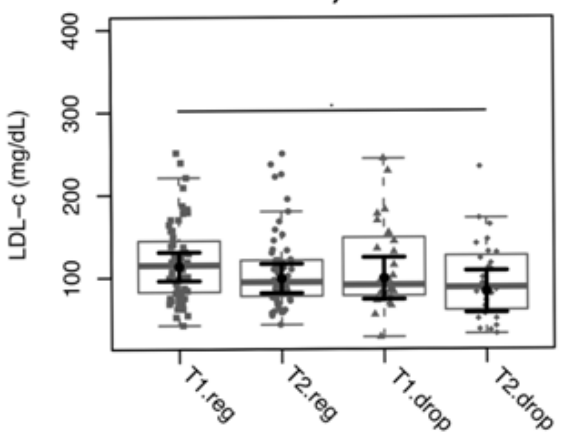

D)

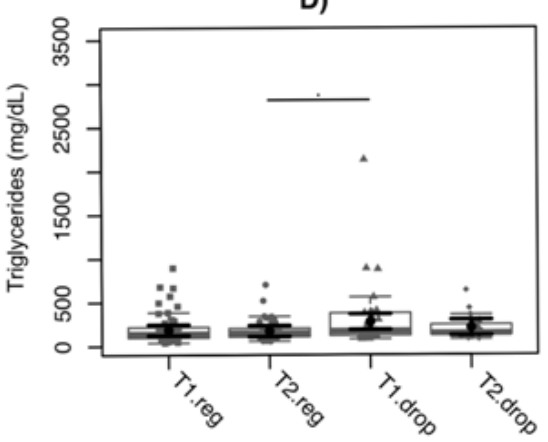

F)

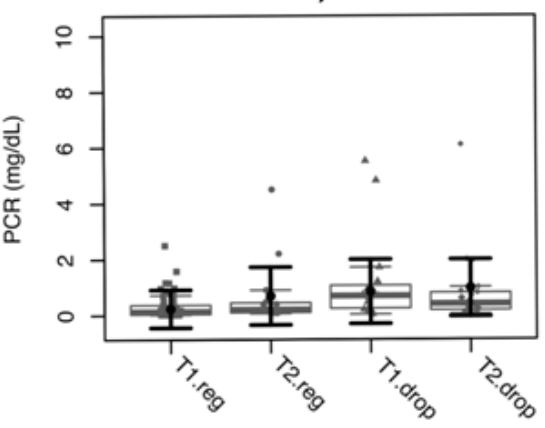

H)

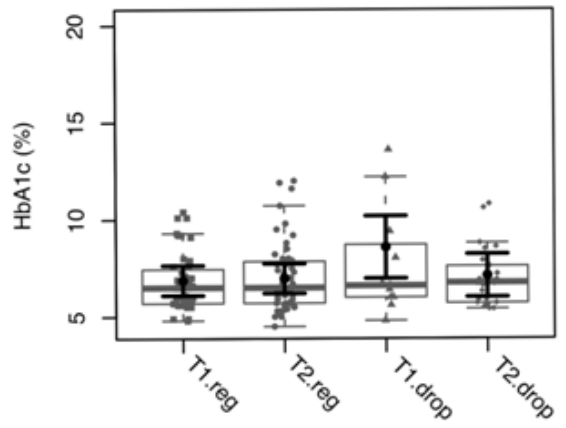

Figure 2

Laboratoryintergroup comparison (REG x DROP) at T2 and T1

The box-plot and strip plot of (A) Total Cholesterol, (B) LDL-C, (C) HDL-C, (D) triglycerides, (E) fasting glucose, (F) PCR, (G) CPK, and (H) HbA1c values in the REG and DROP groups at T1 and T2 are represented in grey. The black central circle represents the expected average marginal effect for each 
group estimated with linear fixed effects models. The fixed effects of the models were the group (REG or DROP), the evaluation time point (T1 or T2), and the first-order interaction between the previous models. The confounding effects included in all models were sex, age, BMI, colour/race, education, marital status and working vs. unemployed status. The black horizontal bars represent the $95 \%$ confidence intervals of the expected mean marginal effects for each group. The $p$ values were corrected for the number of contrasts/two-by-two comparisons using the Tukey honest significant difference (HSD) method. The following values were considered significant: ${ }^{*} p<0.05 ; * \star p<0.01$. Differences were considered suggestive when $p<0.1$. 